\title{
Interaction of Diocleinae Lectins with Glycoproteins Based in Surface Plasmon Resonance
}

\author{
Marcio V Ramos $/^{+}$, Benildo S Cavada*, Anne-Marie Mazard**;, Pierre Rougé $* *$
}

Departamento de Biologia *Departamento de Bioquímica e Biologia Molecular, Universidade Federal do Ceará, Caixa Postal 6033, 60451-970 Fortaleza, CE, Brasil **Institut de Phamacologie et Biologie Structurale, UPR-CNRS n. 9062, Faculté des Sciences Pharmaceutiques, Toulouse, France

Interaction of glucose/mannose-binding lectins in solution with immobilized glycoproteins was followed in real time using surface plasmon resonance technology. The lectins which share many biochemical and structural features could be clearly differentiated in terms of their specificity for complex glycoconjugates. The most prominent interaction of the lectins with PHA-E comparing with soybean agglutinin, both glycoproteins exhibiting high mannose oligosaccharides, suggests that the whole structure of the glycoproteins themselves, may interfere in affinity. These findings also support the hypothesis that minor amino acid replacements in the primary sequence of the lectins might be responsible for their divergence in fine specificity and biological activities. This is the first report using surface plasmon resonance technology that evidences differences of Diocleinae lectins in respect their fine glycan-specificity.

Key words: interaction in real time - lectin - binding-specificity

Extensive studies have been devoted to the carbohydrate-binding specificity of plant lectins (Goldstein \& Poretz 1986). However, although the molecular basis for the monosaccharide-binding specificity of plant lectins is now well documented (Drickamer 1995, Rini 1995), little is known on the extended carbohydrate-binding site of lectins which allows these proteins to specifically recognize oligosaccharides and complex glycans. Following the pioneering results of Bourne et al. $(1990,1992,1994)$ on the two glucose/mannose-specific isolectins of Lathyrus ochrus seeds (Vicieae), a few other results have been reported on EcorL from Erythrina corallodendron (Shaanan et al. 1991), the pea lectin (Rini et al. 1993), GSIV from Griffonia simplicifolia (Delbaere et al. 1993) and the lentil lectin (Loris et al. 1993). Recently, the crystal structure of

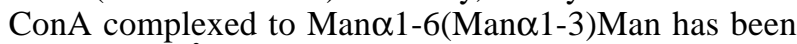
solved at 2.3 Å resolution by Naismith and Field (1996). In addition to the amino acid residues forming the monosaccharide-binding site, other neighbouring residues located at the surface of the lectin also participate in the binding of complex glycans and altogether these residues form an extended carbohydrate-binding site. According to the noteworthy changes occurring in the surface exposed amino acid residues of lectins (Young \& Oomen 1992), a few amino acid replacements could be responsible for the discrepancies of the glycan-binding specificity observed among more or less closely related plant lectins.

The carbohydrate-binding specificity of plant lectins has been classically studied by hapten inhibition of

Supported by CNPq, CNRS and International Foundation for Science.

${ }^{+}$Corresponding author and fellowship of CNPq. Fax: $+55-85-$ 288.9806. E-mail: vramos@ufc.br

Received 18 June 2001

Accepted 14 September 2001 haemagglutination, using various oligosaccharides and complex glycans or glycoconjugates (glycolipids, glycoproteins) as haptenic inhibitors. Surface plasmon resonance, which allows the measurement in real time of the lectin-glycoprotein interactions, now offers a time-saving and more specific alternative to the classical hapten inhibition of haemagglutination. This technique is particularly suitable for revealing subtle differences in the glycan-binding specificities of closely related lectins. In the present work, it was used to discriminate among the glycan-binding specificities of closely related mannose/glucose-specific lectins from the sub-tribe Diocleinae. Even though they are structurally closely related (Ramos et al. 1996a), previous results dealing with the monosaccharide-binding specificity of these lectins have shown that a few discrepancies occur among these proteins (Ramos et al. 1996b).

\section{MATERIALS AND METHODS}

Lectins from Canavalia brasiliensis (ConBr), C. maritima (ConM), Dioclea grandiflora (DGL), D. virgata (DVL) and Cratylia floribunda (CFL) were isolated by affinity chromatography on Sephadex G-50 (Pharmacia), as previously described (Moreira et al. 1983, Moreira \& Cavada, 1984, Oliveira et al. 1991). Con A (Type IV), carbohydrates, glycoproteins and chemicals were purchased from Sigma Chemicals Co. (St Louis, USA).

For the amino acid sequence comparison of the Diocleinae lectins, the amino acid sequences of Con A (Jones, D.H., EMBL ID CECONA1, EMBL AC X01632), ConG from C. gladiata (Yamauchi et al. 1989), ConL from C. lineata (Fujimura et al. 1993), ConM from C. maritima (Perez et al. 1991), ConV from C. virosa (Fujimura et al. 1993), DGL from $D$. grandilfora (Richardson et al. 1984) and DLL from D. lehmanni (Perez et al. 1991) were taken from the corresponding references. The amino acid sequence alignments were carried on a MicroVAX 3100 (Digital, Evry, France) using the Ialign program of PIR/NBRF (Washington, USA). The program SeqVu (Gardner J, 1995, 
The Garvan Institute of Medical Research, Sydney, Australia) was used to compare the amino acid sequences of the Diocleinae lectins.

Specific-interaction analyses of lectins with various glycoproteins [PHA-E, SBA, arcelin-1 (ARCE-1), hen ovalbumin (OVA), orosomucoid or acid $\alpha$-glycoprotein (ORO), ovomucoid (OVO), bovine lactotransferrin (BLT) and human serotransferrin (HST)] were performed by surface plasmon resonance (SPR) using a biosensor BIAcore (Pharmacia Biosensor AB). The lectins, used at concentrations ranging from 0.25 up to $100 \mu \mathrm{g} . \mathrm{ml}^{-1}$ in $\mathrm{HBS} \mathrm{pH}$ 7.4 , were injected for $5 \mathrm{~min}$ onto the glycoprotein-bound surface of the sensor chip at a flow rate of $5 \mu \mathrm{g} \cdot \mathrm{ml}^{-1}$. Intensity of interaction which traduces affinity, was considered as the difference between values of arbitrary resonance units (RU) at the moment of injection and the beginning and the end of dissociation phase. The change of the SPR response, (RU), was monitored at $25^{\circ} \mathrm{C}$ for 9.30 $\min$. The same glycoprotein sensor chip surface was used repeatedly after removing the remaining immobilized lectins by two successive washes with $10 \mathrm{mM} \mathrm{HCl}$ and 10 $\mathrm{mM}$ NAOH for $2 \mathrm{~min}$ each. The immobilized glycoproteins predominantly contain glycans of the high-mannose type (PHA-E, SBA, ARCE-1, OVA, OVO, BLT) and complex glycans of the $\mathrm{N}$-acetyllactosaminic type (ORO, HST) (Montreuil 1984). All these glycoproteins exhibit a more or less exposed trimannoside core Man $\alpha 1-6$ (Man $\alpha 1-$ 3)Man which was shown to specifically interact with the extended carbohydrate-binding site of Con A (Naismith \& Field 1996).

For immobilization, glycoproteins were used at a concentration of $1 \mathrm{mg} \cdot \mathrm{ml}^{-1}$ in $5 \mathrm{mM}$ sodium acetate buffer $\mathrm{pH}$ 4.0. According to the change of SPR response, expressed in resonance units (RU), as a result of the immobilization of the glycoproteins on the carboxymethylated dextran layer covering the sensor chip, an estimated surface concentration of $10 \mathrm{ng} \cdot \mathrm{mm}^{-2}$ of dextran was obtained for the immobilized proteins. Sensor chips (CM 5) and all the chemicals required for the activation of the carboxymethylated dextran and the immobilization of glycoproteins (100 mM $N$-hydroxysuccinimide, 400 mM N-ethylN'-(3-dimethylaminopropyl) carbodiimide hydrochloride, and $1 \mathrm{M}$ ethanolamine hydrochloride adjusted to $\mathrm{pH} 8.5$ with $\mathrm{NAOH}$ ) were obtained from Pharmacia Biosensor AB. HBS (10 mM Hepes, pH 7.4, $150 \mathrm{mM} \mathrm{NaCl}$, containing $0.05 \% \mathrm{BlAcore}$ surfactant P20) used for the biosensor measurements, was from Pharmacia Biosensor AB. Surface plasmon resonance technology has been largely used to study interaction and affinity between biomolecules, based solely in the comparison of sensorgrammes produced by the real time interaction analysis, although a complete kinetic of the interaction can be determined if all parameter required are controlled (Raghavan \& Bjorkman 1995, Haseley et al. 1999, Rich \& Myszka 2000).

\section{RESULTS}

As shown from surface plasmon resonance measurements, various lectins from the Diocleinae sub-tribe interacted with all of the glycoproteins used as glycan probes. However, great discrepancies occurred according to the glycoproteins used (Fig. 1). In this respect the lectins strongly reacted with glycoproteins containing more or less branched glycans of the high-mannose type, e.i. PHAE and ARCE-1 from P. vulgaris, BLT, OVA and SBA. A very strong interaction was observed with the highly branched high mannose glycans of PHA-E and ARCE-1. They interact to a lower extent with glycoproteins bearing glycans of the complex or $N$-acetyllactosaminic type, i.e. ORO, OVO and HST.

Some discrepancies also occurred when comparing the different Diocleinae lectins (Fig. 2). ConBr and DGL interacted with PHA-E and ARCE-1 more strongly than the other checked lectins. CFL highly reacted with BLT while ConBr, ConM and DGL were the most reactive lectins towards OVA. The Diocleinae lectins exhibited similar interaction with SBA, except for ConBr and ConM which were the most reactive. Similarly, the interaction with ORO was weak, except for ConBr and DVL. Finally, all checked lectins interacted very weakly with the complex glycancontaining glycoproteins, OVO and HST. Surprisingly, ConBr reacted more strongly than other Diocleinae lectins with almost all of the assayed glycoproteins.

Hapten inhibition experiments of the glycoprotein-lectin interaction (e.g. ARCE1/ConM) performed by monitoring the effects of increasing amounts of $\alpha 1-3, \alpha 1-6$ Mannotriose (triMan3,6) added during the dissociation phase, showed a significant decrease of the previously bound ConM (result not shown), thus indicating that the interaction of the lectins with the oligomannosidic moiety of the glycoproteins is highly specific. In addition, these results suggest that the lectin-glycoprotein interaction mostly depends on the recognition of more or less extended glycans by the lectins since the inhibition occurring with simple sugars, e.g. mannose, is far from being so pronounced.

\section{DISCUSSION}

The glycan-binding specificity of ConA was previously investigated by measuring the retardation of labelled

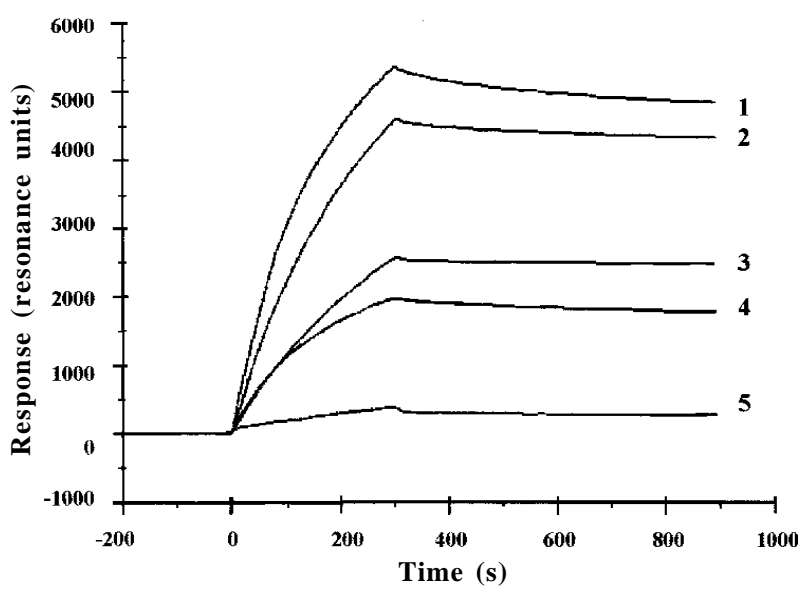

Fig. 1: sensorgramme showing the interaction of circulating $\mathrm{ConBr}$ with immobilized PHA-E (1), ARCE-1 (2), BLT (3), SBA (4), and HST (5). For each curve, the increasing portion corresponds to the association phase (presence of lectin into the circulating buffer) while the decreasing portion corresponds to the dissociation phase (no lectin into the circulating buffer) 


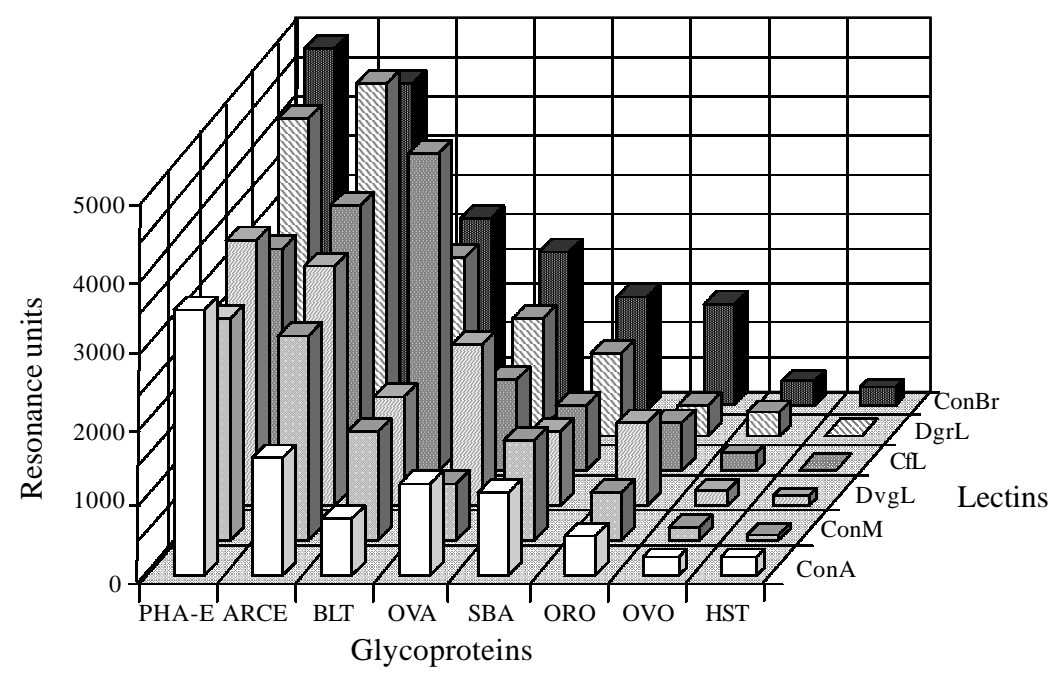

Fig. 2: interaction (measured as resonance units) of different circulating lectins (ConA, ConBr, ConM, CFL, DGL and DVL) used at a constant concentration of $100 \mu \mathrm{g} \cdot \mathrm{ml}^{-1}$ in $\mathrm{HBS}$ pH 7.4 with various immobilized glycoproteins: PHAE-E, ARCE, BLT, SBA and HST as in Fig. 1. OVA (Ovalbumin); ORO (Orosomucoid) and OVO (Ovomucoid)

glycans passing through a column of insolubilized lectin (Debray et al. 1981, 1983). This lectin was shown to specifically recognize glycans of both the high mannose and the complex or $N$-acetyllactosaminic types. ConA interacts with glycans of the $N$-acetyllactosaminic type by a pentasaccharide corresponding to the trimannoside core Man $\alpha$ l-6(Man $\alpha$ l-3)Man substituted by two $\beta(1-2)$ linked GlcNAc. It also interacts with the exposed non-reducing $\alpha(1-2)$ linked Man residues of the high-mannose type glycans.

The structural basis for the interaction of ConA with the trimannoside core Man $\alpha 1-6($ Mano1-3)Man has been investigated by Naismith and Field (1996). The specific recognition of the trimannoside core by ConA depends on the interaction of the extended binding site of the lectin with both the reducing and $\alpha 1,3$-linked mannose units. A network of hydrogen bonds involving residues Tyr ${ }^{12}$, $\mathrm{Asn}^{14}, \mathrm{Thr}^{15}, \mathrm{Asp}^{16}, \mathrm{Leu}^{99}, \mathrm{Tyr}^{100}, \mathrm{Asp}^{208}$ and $\mathrm{Arg}^{228}$ interact with the hydroxyls of the three mannose units. In addition, the interaction is completed by Van der Waals contacts occurring between the mannose units and residues Tyr ${ }^{12}$, Pro $^{13}$, Asn $^{14}$, Thr $^{15}$, Asp $^{16}$, Gly $^{98}$, Leu $^{99}$, Tyr $^{100}$, $\mathrm{Ala}^{207}, \mathrm{Asp}^{208}, \mathrm{Gly}^{227}$ and $\mathrm{Arg}^{228}$. Although some of the amino acid residues forming the extended binding site of Con A are identical or homologous to those found in PsA (Rini et al. 1993) and LoLI (Bourne et al. 1994), this binding pattern is substantially different since three polar residues $\left(\mathrm{Tyr}^{12}, \mathrm{Asp}^{16}\right.$ and $\mathrm{Arg}^{228}$ ) replace non polar residues (Phe, Ala and Gly) in both PsA and LoLI. All the amino acid residues of ConA involved in both the hydrogen bonds and Van der Waals contacts are conserved in other Diocleinae lectins of known amino acid sequences (Fig. 3).

The most striking result concerns the discrepancies observed among the glycan-binding affinities of the assayed Diocleinae lectins. In this respect, $\mathrm{ConBr}$ appears as the most reactive lectin while ConA or ConM often react more weakly with the glycoproteins. Obviously, these discrepancies are difficult to explain on the basis of the very limited amino acid changes observed when the amino acid sequences of the different Diocleinae lectins are compared (see Fig. 3). However, according to Young and Oomen (1992), a few amino acid changes occurring in the vicinity of the monosaccharide-binding site could be responsible for the distinct glycan-binding specificities of closely related lectins. Except for two of them $\left(\mathrm{Val}^{17}\right.$ in ConM, which replaces a Leu residue in other lectins; $\operatorname{Ser}^{162}$ in DGL and Asp ${ }^{162}$ in DLL, which replace an Asn residue in other lectins), all the other hyper variable residues over a total of 17 residues located around the monosaccharide-binding pocket are strictly conserved in all the Diocleinae lectins. Accordingly, the very conserved character of both the monosaccharide-binding site and the surface-exposed surrounding residues can not account for the observed glycan-binding affinities.

Recently, the crystal structure of ConBr was solved at 3.0 Å resolution (Sanz-Aparicio et al. 1997) and, although its monomer could be well superposed to that of ConA (rms of $0.65 \AA$ ), some discrepancies were observed when the superpositions of $\mathrm{ConBr}$ and ConA dimers (rms of $0.84 \AA$ ) and tetramers (rms of $1.62 \AA$ ) were performed. These differences in the quaternary structures may account for the quite distinct biological properties exhibited by these two lectins (Barral-Netto et al. 1992, Rodriguez et al. 1992, Bento et al. 1993, Gomes et al. 1994, Ferreira et al. 1996). Similarly, they could account for the reported discrepancies in the lectin-glycoprotein interactions.

Lectins from the Diocleinae sub-tribe thus exhibit very different glycan-affinities and biological properties, although they share very similar amino acid sequences and monomeric structures. They constitute an interesting example of proteins whose the structure-function relation- 


\begin{tabular}{|c|c|c|}
\hline $\begin{array}{l}\text { ConA } \\
\text { ConBr } \\
\text { ConG } \\
\text { ConL } \\
\text { ConM } \\
\text { Conv } \\
\text { DGL }\end{array}$ & $\begin{array}{l}1 \\
1 \\
1 \\
1 \\
1 \\
1 \\
1 \\
1\end{array}$ & 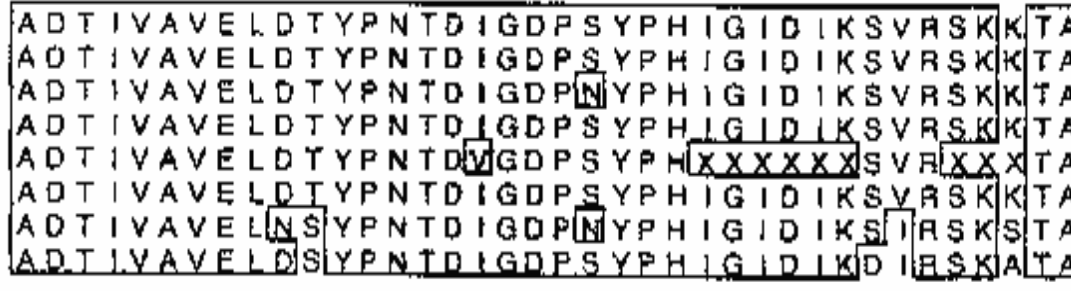 \\
\hline $\begin{array}{l}\operatorname{Con} A \\
\operatorname{ConBr} \\
\operatorname{ConG} \\
\operatorname{ConL} \\
\operatorname{ConM} \\
\operatorname{Con} V \\
\text { DGL } \\
\text { DLL }\end{array}$ & $\begin{array}{l}41 \\
41 \\
41 \\
41 \\
41 \\
41 \\
41 \\
41\end{array}$ & 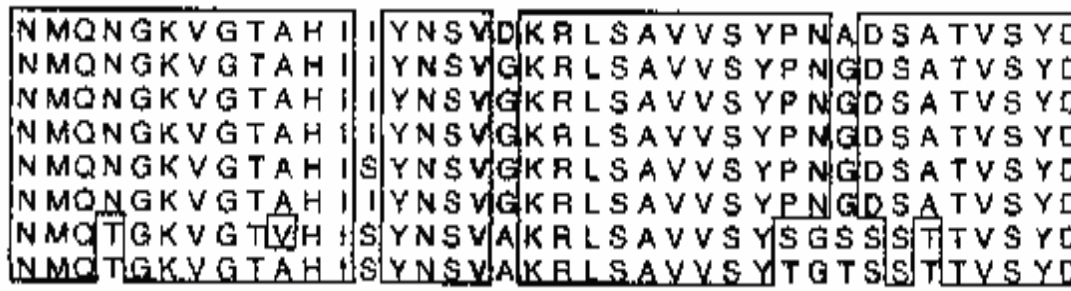 \\
\hline $\begin{array}{l}\text { ConA } \\
\text { ConBr } \\
\text { Cong } \\
\text { ConL } \\
\text { ConM } \\
\text { ConV } \\
\text { DGL } \\
\text { DLL }\end{array}$ & $\begin{array}{l}81 \\
81 \\
81 \\
81 \\
81 \\
81 \\
81 \\
81\end{array}$ & 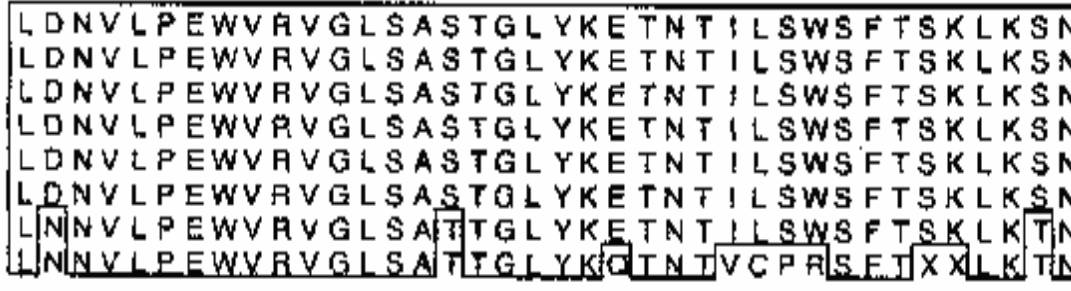 \\
\hline $\begin{array}{l}\text { ConA } \\
\text { ConBr } \\
\text { Cong } \\
\text { ConL } \\
\text { ConM } \\
\text { ConV } \\
\text { DGL. } \\
\text { DLL }\end{array}$ & $\begin{array}{l}121 \\
121 \\
12 t \\
121 \\
12 t \\
121 \\
121 \\
+21\end{array}$ & 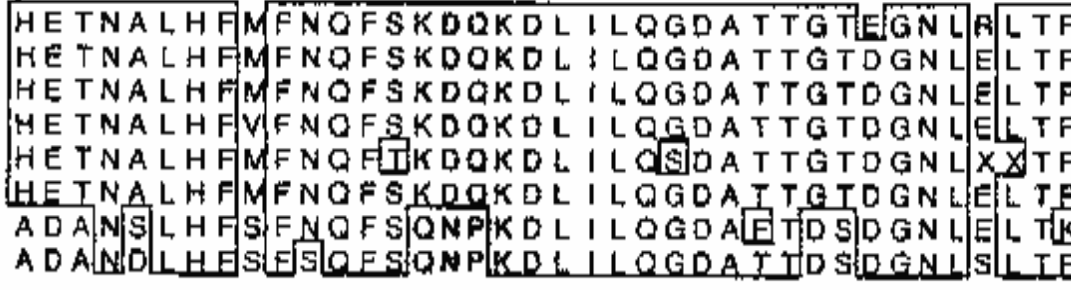 \\
\hline $\begin{array}{l}\text { ConA } \\
\text { ConBr } \\
\text { ConG } \\
\text { ConL } \\
\text { ConM } \\
\text { Conv } \\
\text { DGi } \\
\text { DLL }\end{array}$ & $\begin{array}{l}101 \\
161 \\
181 \\
181 \\
161 \\
181 \\
161 \\
181\end{array}$ & 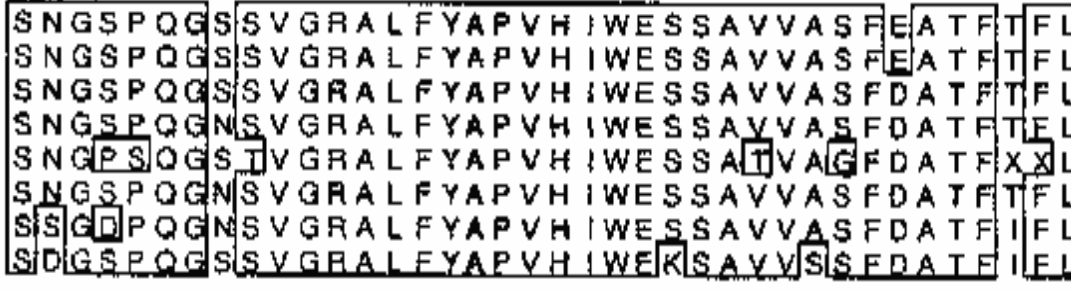 \\
\hline $\begin{array}{l}\text { ConA } \\
\text { ConBr } \\
\text { ConG } \\
\text { ConL. } \\
\text { ConM } \\
\text { ConV } \\
\text { DGL } \\
\text { DLL }\end{array}$ & $\begin{array}{l}201 \\
201 \\
201 \\
201 \\
201 \\
201 \\
201 \\
201\end{array}$ & 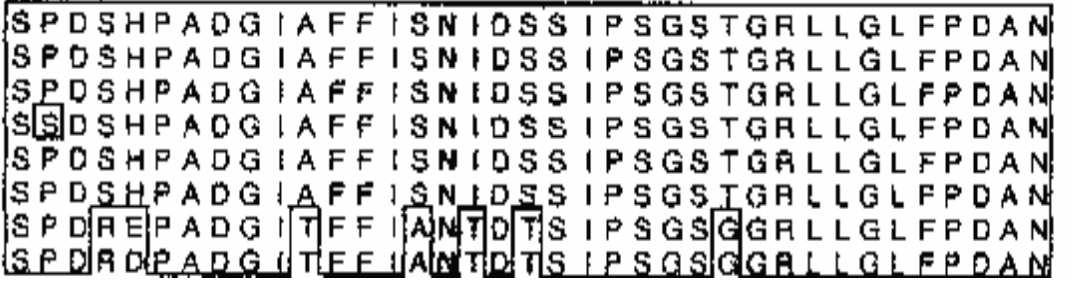 \\
\hline
\end{tabular}

Fig. 3: comparison of the amino acid sequences of ConA from Canavalia ensiformis, ConBr from C. brasiliensis, ConG from C. gladiata, ConL from C. lineata, ConM from C. maritima, ConV from C. virosa, DGL from Dioclea grandiflora and DLL from D. lehmanni. Identical residues are in box.

ship mainly depends on the quaternary arrangement of its monomers.

\section{REFERENCES}

Barral-Netto M, Santos SB, Baffal A, Moreira LI, Santos CF, Moreira RA, Oliveira JTA, Cavada BS 1992. Human lymphocyte stimulation by legume lectins from the Diocleae tribe. Immunol Invest 21: 297-303.

Bento CA, Cavada BS, Oliveira JTA, Moreira RA, Barja-Fidalgo
C 1993. Rat paw edema and leukocyte immigration induced by plant lectins. Agents Actions 38: 48-54.

Bourne Y, Rougé P, Cambillau C 1990. X-ray structure of a (alpha-Man(1-3)beta-Man(1-4)GlcNAc)-lectin complex at 2.1-A resolution. The role of water in sugar-lectin interaction. J Biol Chem 265: 18161-18165.

Bourne Y, Rougé P, Cambillau C 1992. X-ray structure of a biantennary octasaccharide-lectin complex refined at 2.3-A resolution. J Biol Chem 267: 197-203. 
Bourne Y, Mazurier J, Legrand D, Rougé P, Montreuil J, Spik G, Cambillau C 1994. Structures of a legume lectin complexed with the human lactotransferrin N2 fragment, and with an isolated biantennary glycopeptide: role of the fucose moiety. Structure 2: 209-219.

Debray H, Decout D, Strecker G, Spik G, Montreuil J 1981. Specificity of twelve lectins towards oligosaccharides and glycopeptides related to N-glycosylproteins. Eur J Biochem 117: 41-55.

Debray H, Pierce-Crétel G, Spik G, Montreuil J 1983. Affinity of tem insolubilized lectins towards various glycopeptides with the $\mathrm{N}$-glycosylamine linkage and related oligosaccharides. In TC Bog-Hansen, GA Spegler (eds), Lectins: Biology, Biochemistry, Clinical Biochemistry, Walter de Gruyter, Berlin, New York, p. 335-350.

Delbaere LTJ, Vandonselaar M, Prasad L, Quail JW, Wilson KS, Dauter Z 1993. Structures of the lectin IV of Griffonia simplicifolia and its complex with the Lewis b human blood group determinant at 2.0 A resolution. J Mol Biol 230: 950965.

Drickamer K 1995. Multiplicity of lectin-carbohydrate interactions. Nature Struct Biol 2: 437-439.

Ferreira RR, Cavada BS, Moreira RA, Oliveira JTA, Gomes JC 1996. Characteristics of the histamine release from hamster cheek pouch mast cells stimulated by lectins from Brazilian beans and concanavalin A. Inflamm Res 45: 442-447.

Fujimura S, Terada S, Jayavardhanan KK, Panikkar KR, Kimoto E 1993. Primary structures of concanavalin A-like lectins from seeds of two species of Canavalia. Phytochem 33: 985-987.

Goldstein IJ, Poretz RD 1986. Isolation, physicochemical characterization and carbohydrate-binding specificity of lectins. In IE Liener, N Sharon, IJ Goldstein (eds), The Lectins, Properties, Functions, and Applications in Biology and Medicine, Academic Press, New York, p. 33-247.

Gomes JC, Ferreira RR, Cavada BS, Moreira RA, Oliveira JTA 1994. Histamine release induced by glucose (mannose)-specific lectins isolated from Brazilian beans. Comparison with concanavalin A. Agents Actions 41: 132-135.

Haseley SR, Talaga P, Kamerling JP, Vliegenthart JFG 1999. Characterization of the carbohydrate binding specificity and kinetic parameters of lectins by using surface plasmon resonance. Anal Biochem 274: 203-210.

Loris R, Thi MHD, Lisgarten J, Wyns L 1993. Purification, crystallization, and preliminary $\mathrm{X}$-ray studies on the rhizome lectin from stinging nettle and its complex with NN'N"-triacetylchitotriose. Proteins 15: 205-208.

Montreuil J 1984. Spatial conformation of glycans and glycoproteins. Biol Cell 51: 115-132.

Moreira RA, Cavada BS 1984. Lectin from Canavalia brasiliensis (Mart.). Isolation, characterization and behavior during germination. Biol Plantarum 26: 113-120.

Moreira RA, Barros ACH, Stewart JC, Pusztai A 1983. Isolation and characterization of a lectin from the seeds of Diolcea grandiflora (Mart.) Planta 158: 63-69.
Naismith JH, Field RA 1996. Structural basis of trimannoside recognition by concanavalin A. J Biol Chem 271: 972-976.

Oliveira JTA, Cavada BS, Moreira RA 1991. Isolation and partial characterization of a lectin from Cratylia floribunda Mart. seeds. Revta brasil Bot 14: 61-66.

Perez G, Perez C, Sousa-Cavada B, Moreira RA, Richardson M 1991. Comparison of the amino acid sequences of the lectins from seeds of Dioclea lehmanni and Canavalia maritima. Phytochem 30: 2619-2621.

Raghavan M, Bjorkman PM 1995. BIAcore: a microchip-based system for analyzing the formation of macromolecular complexes. Curr Biol 3: 331-333.

Ramos MV, Moreira RA, Oliveira JTA, Cavada BS, Rougé P 1996a. Structural similarities among Diocleinae lectins. In E Van Driessche, P Rougé, S Beeckmans, TC Bog-Hansen (eds), Lectins: Biology, Biochemistry, Clinical Biochemistry. Textop, Hellerup, DK, p. 44-49.

Ramos MV, Moreira RA, Oliveira JTA, Cavada BS, Rougé P 1996b. The carbohydrate-binding specificity and molecular modelling of Canavalia maritima and Dioclea grandiflora lectins. Mem Inst Oswaldo Cruz 91: 761-766.

Rich RC, Myszka DG 2000. Advances in surface plasmon resonance biosensor analysis. Curr Opin Biotech 11: 54-61.

Richardson M, Campos FDAP, Moreira RA, Ainouz IL, Begbie R, Watt WB, Pusztai A 1984. The complete amino acid sequence of the major alpha subunit of the lectin from the seeds of Dioclea grandiflora (Mart). Eur J Biochem 144: 101-111.

Rini JM 1995. Lectin structure. Annu Rev Biophys Biomol Struct 24: 551-577.

Rini JM, Hardman KD, Einspahr H, Suddath FL, Carver JP 1993. X-ray crystal structure of a pea lectin-trimannoside complex at 2.6 A resolution. J Biol Chem 268: 10126-10132.

Rodriguez D, Cavada BS, Oliveira JTA, Moreira RA, Russo M 1992. Differences in macrophage stimulation and leukocyte accumulation in response to intraperitoneal administration of glucose/mannose-binding plant lectins. Braz J Med Biol Res 25: 823-826.

Sanz-Aparicio J, Hermoso J, Grangeiro TB, Calvete JJ, Cavada BS 1997. The crystal structure of Canavalia brasiliensis lectin suggests a correlation between its quaternary conformation and its distinct biological properties from Concanavalin A. FEBS Lett 405: 114-118.

Shaanan B, Lis H, Sharon N 1991. Structure of a legume lectin with an ordered N-linked carbohydrate in complex with lactose. Science 254: 862-866.

Yamauchi D, Nakamura K, Asahi T, Minamikawa T 1989. cDNAs for canavalin and concanavalin A from Canavalia gladiata seeds. Nucleotide sequence of cDNA for canavalin and RNA blot analysis of canavalin and concanavalin A mRNAs in developing seeds. $P$ Cell Physiol 30: 147-150.

Young NM, Oomen RP 1992. Analysis of sequence variation among legume lectins. A ring of hypervariable residues forms the perimeter of the carbohydrate-binding site. J Mol Biol 228: 924-934. 
Interaction of Lectins and Glycoproteins • Márcio V Ramos et al. 